Atomic Force Microscope (AFM)

measurements and analysis on Tinsley AIA-1000-003 primary substrate

R. Soufli, S. L. Baker, J. C. Robinson

May 24, 2006 
This document was prepared as an account of work sponsored by an agency of the United States Government. Neither the United States Government nor the University of California nor any of their employees, makes any warranty, express or implied, or assumes any legal liability or responsibility for the accuracy, completeness, or usefulness of any information, apparatus, product, or process disclosed, or represents that its use would not infringe privately owned rights. Reference herein to any specific commercial product, process, or service by trade name, trademark, manufacturer, or otherwise, does not necessarily constitute or imply its endorsement, recommendation, or favoring by the United States Government or the University of California. The views and opinions of authors expressed herein do not necessarily state or reflect those of the United States Government or the University of California, and shall not be used for advertising or product endorsement purposes.

This work was performed under the auspices of the U.S. Department of Energy by University of California, Lawrence Livermore National Laboratory under Contract W-7405-Eng-48. 


\section{Atomic Force Microscope (AFM) measurements and analysis on Tinsley AlA-1000-003 primary substrate}

Regina Soufli, Sherry Baker, and Jeff C. Robinson October 20, 2005 -January 13, 2006 


\section{Map of AFM measurement locations on AIA-1000-003}

\section{Tinsley primary mirror}

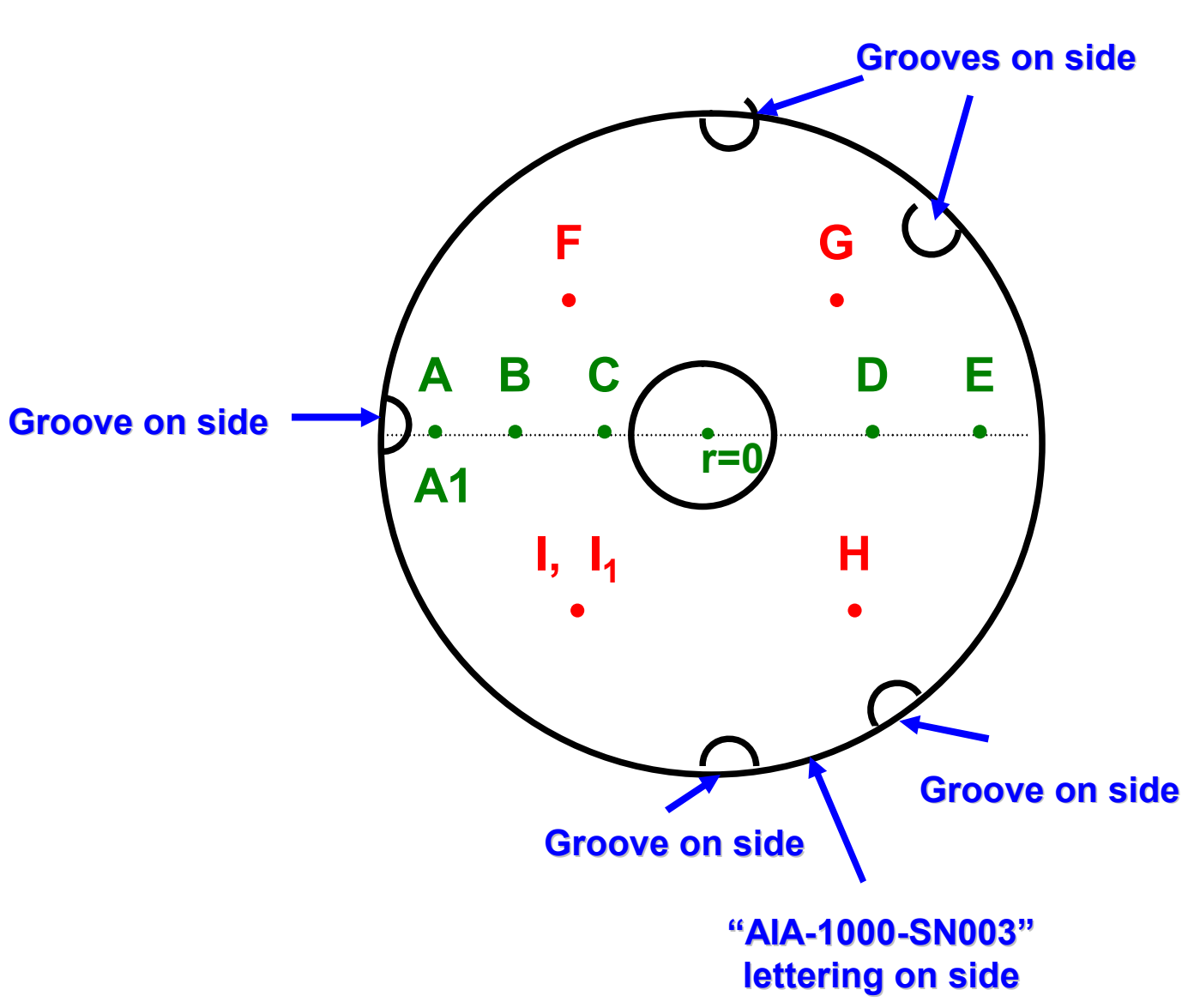

\begin{tabular}{|c|c|}
\hline Location & $\begin{array}{l}\text { Radius } \\
r(\mathrm{~mm}) \text { from } \\
\text { mirror center }\end{array}$ \\
\hline A & 92 \\
\hline B & 69.5 \\
\hline C & 47 \\
\hline D & 58.3 \\
\hline E & 80.8 \\
\hline F, G, H, I, I & 65 \\
\hline
\end{tabular}

Locations A, B, C, D, E, measured on October 10, 2005

Locations F, G, H, I, I, measured on January 13, 2006

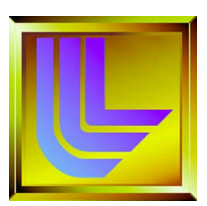




\section{AFM images from Tinsley AIA-1000-003 primary}

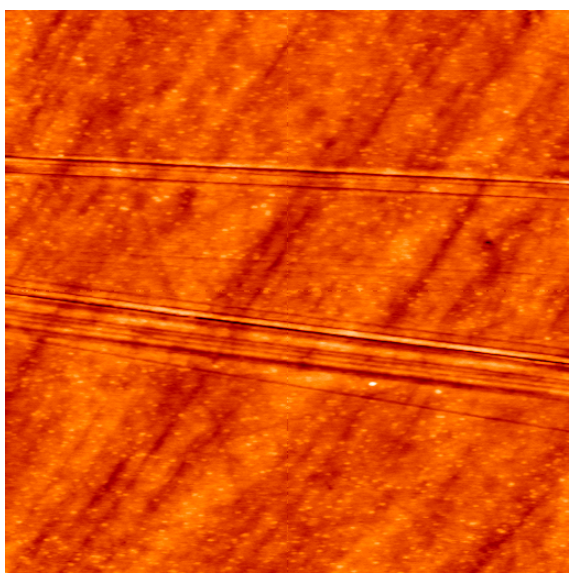

$2 \times 2 \mu \mathrm{m}^{2}$, loc. A

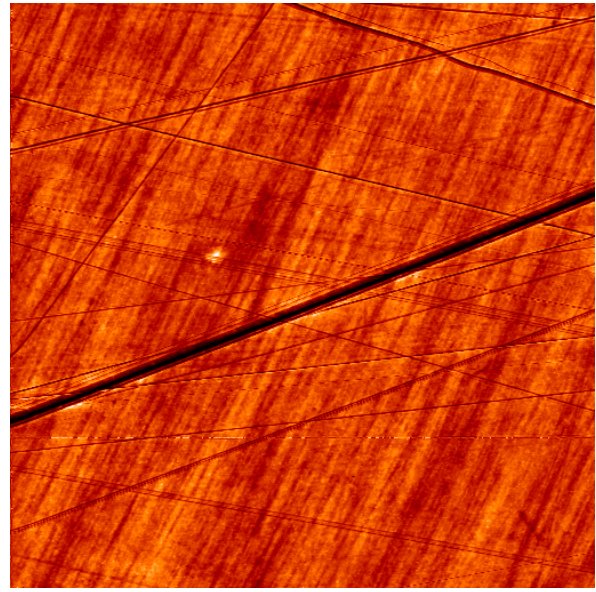

$10 \times 10 \mu \mathrm{m}^{2}$, loc. $A$

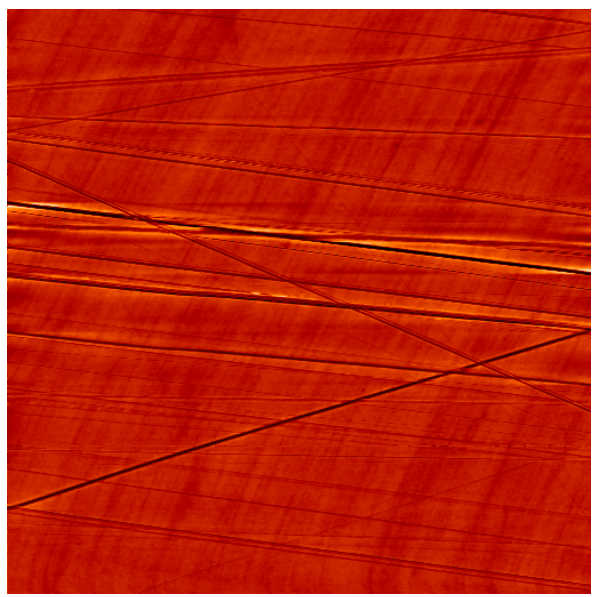

$10 \times 10 \mu \mathrm{m}^{2}$, loc. A1 (about $50 \mu \mathrm{m}$ below Ioc. A)

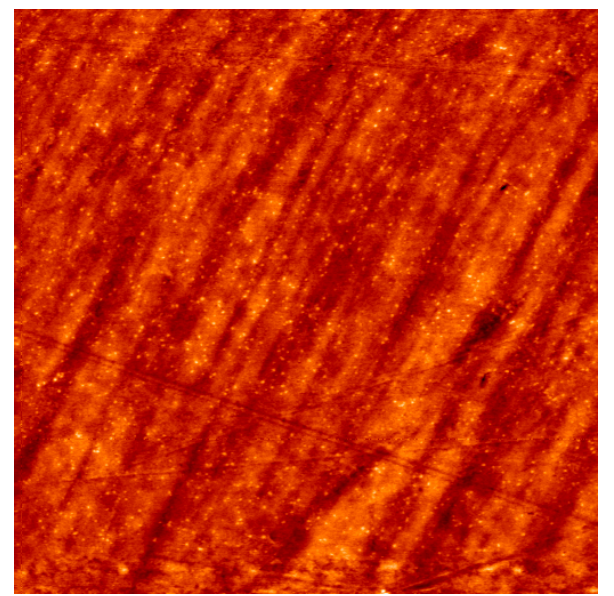

$2 \times 2 \mu \mathrm{m}^{2}$, loc. $B$

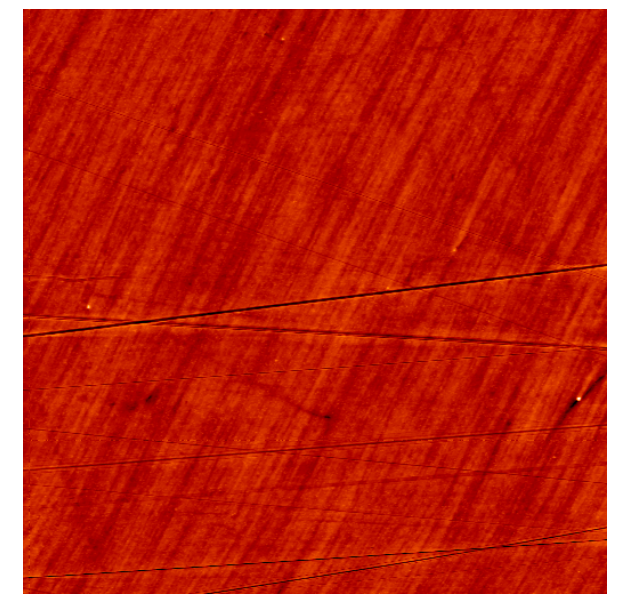

$10 \times 10 \mu \mathrm{m}^{2}$, loc. B

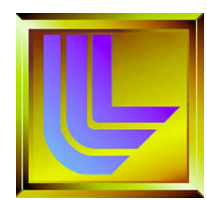

Regina Soufli et al, 10/20//05-01/13/06 


\section{AFM images from AIA-1000-003 primary}

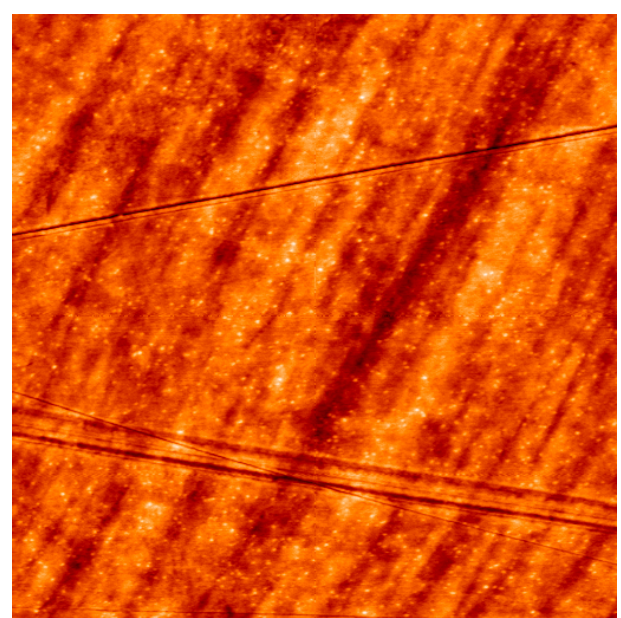

$2 \times 2 \mu \mathrm{m}^{2}$, loc. C

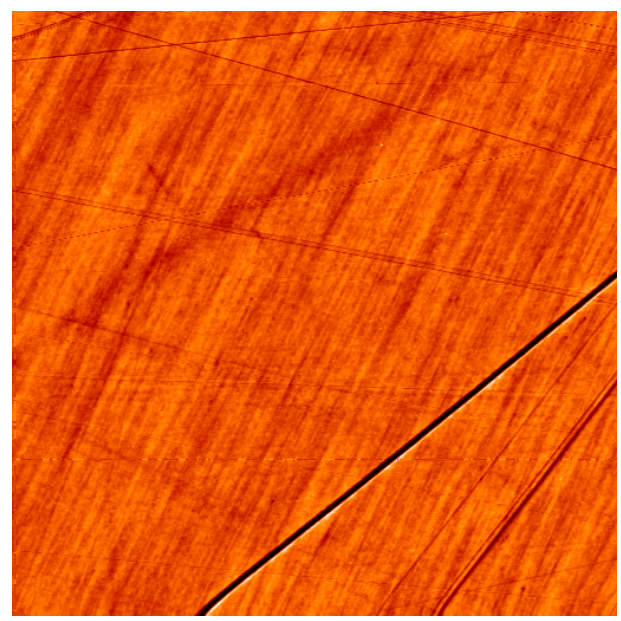

$10 \times 10 \mu \mathrm{m}^{2}$, loc. $\mathrm{C}$

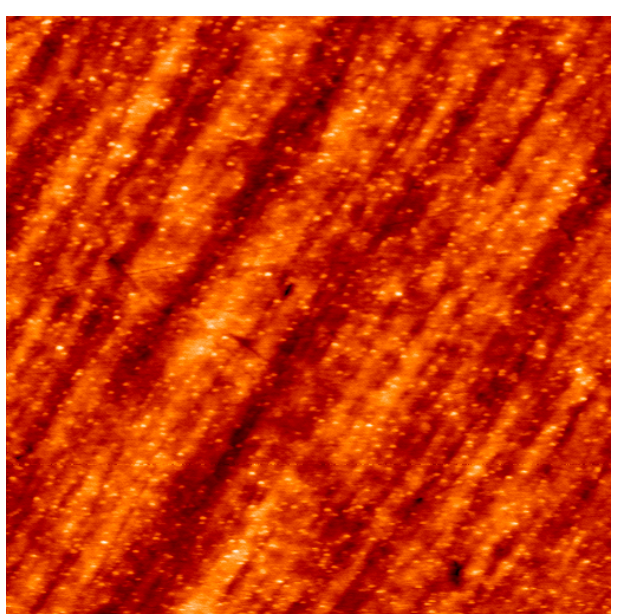

$2 \times 2 \mu \mathrm{m}^{2}$, loc. $\mathrm{D}$

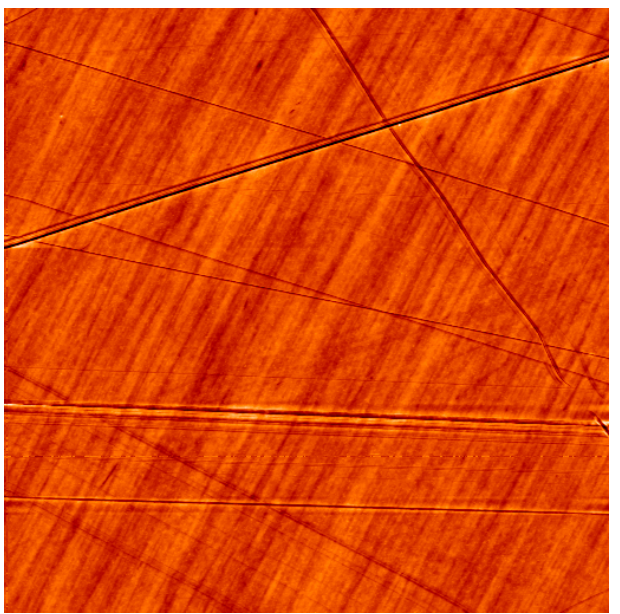

$10 \times 10 \mu \mathrm{m}^{2}$, loc. $D$

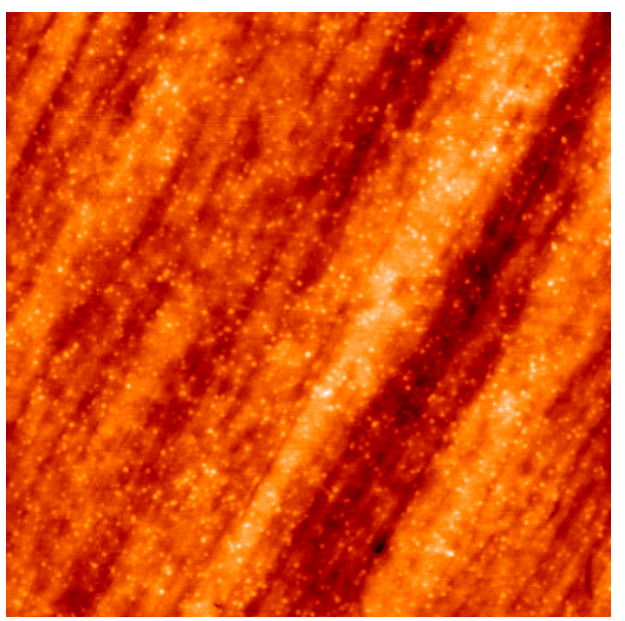

$2 \times 2 \mu \mathrm{m}^{2}$, loc. $E$

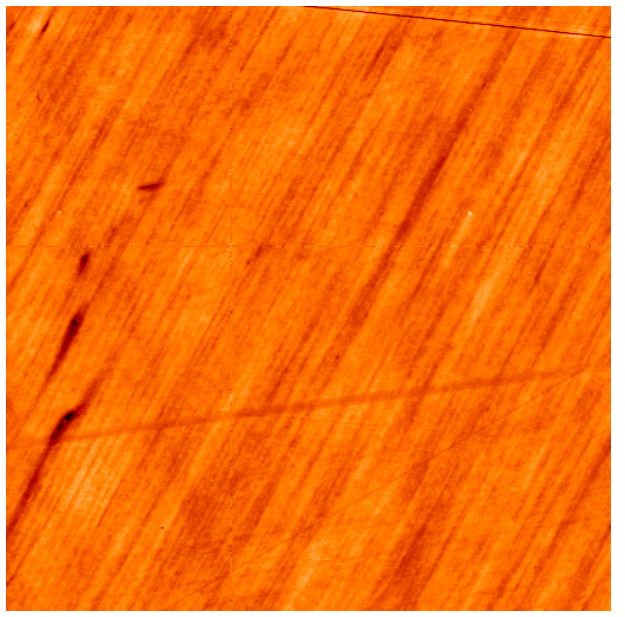

$10 \times 10 \mu \mathrm{m}^{2}$, loc. $E$

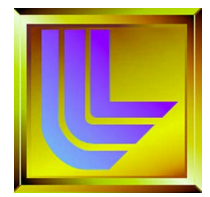




\section{AFM images from Tinsley AIA-1000-003 primary}

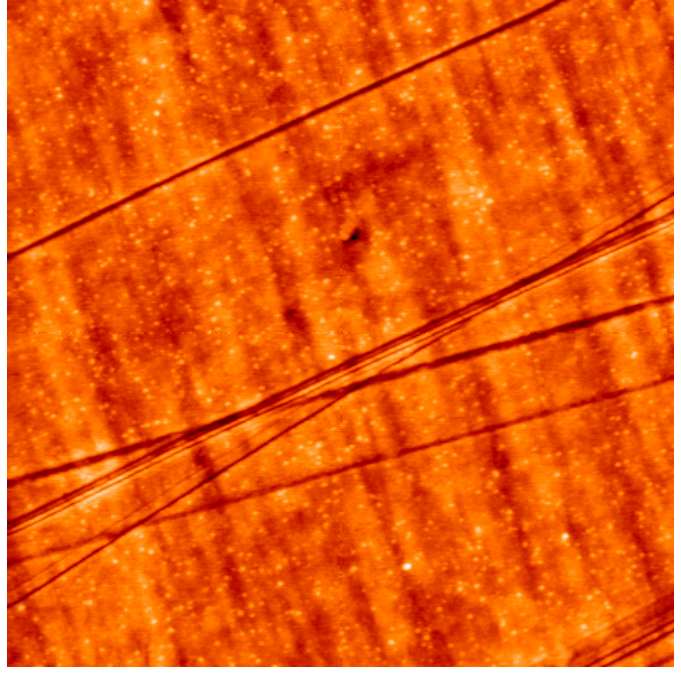

$2 \times 2 \mu \mathrm{m}^{2}$, loc. $\mathrm{F}$

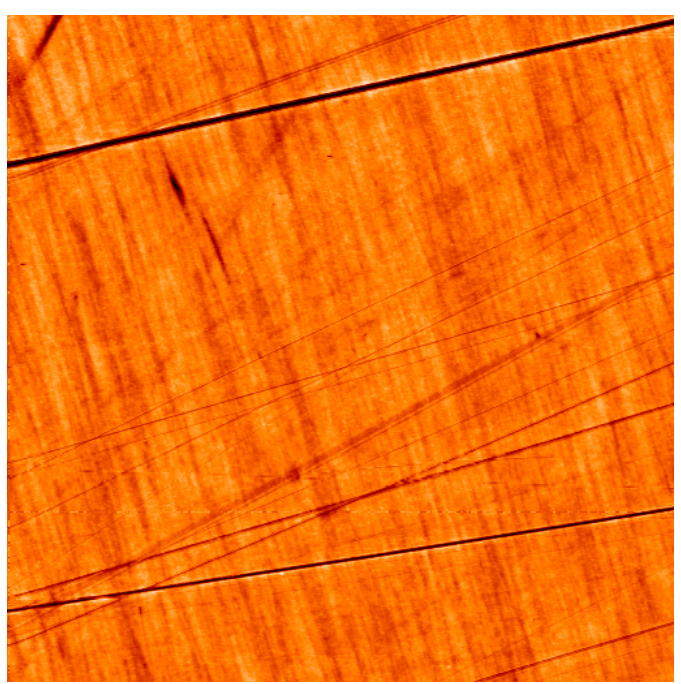

$10 \times 10 \mu \mathrm{m}^{2}$, loc. $F$

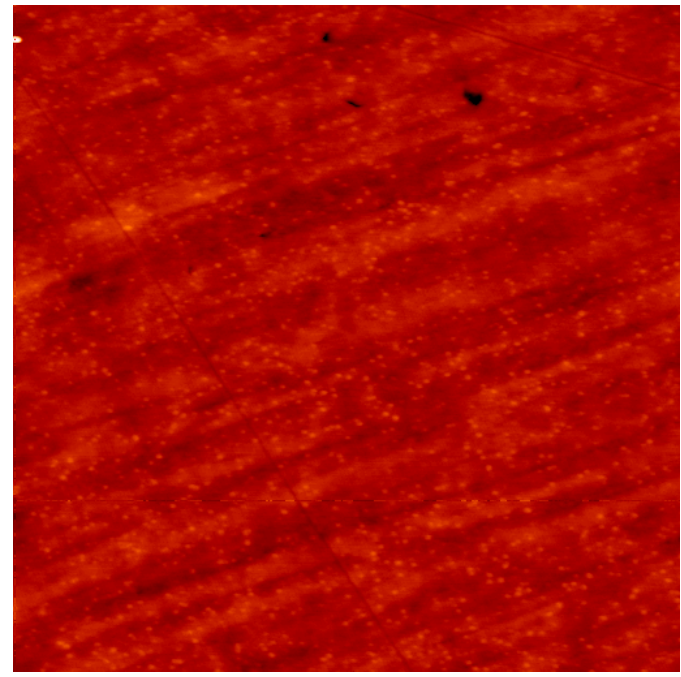

$2 \times 2 \mu \mathrm{m}^{2}$, loc. $\mathbf{G}$

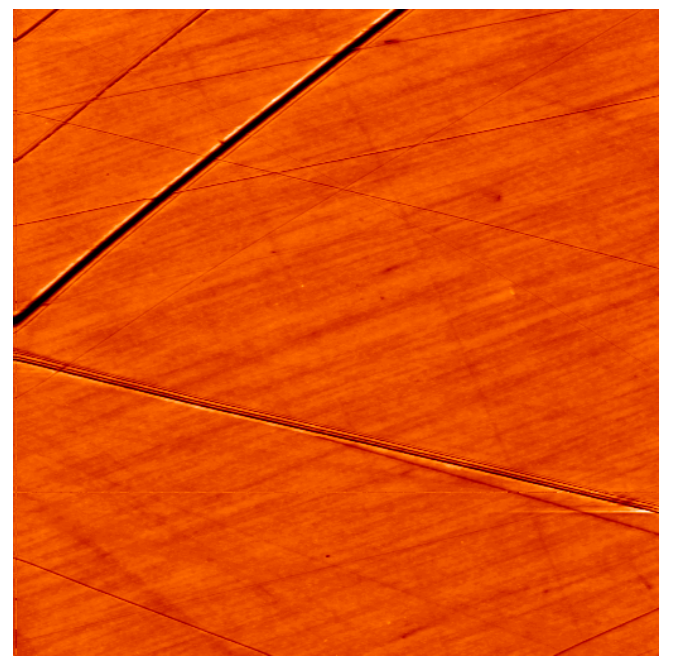

$10 \times 10 \mu \mathrm{m}^{2}$, loc. $\mathbf{G}$

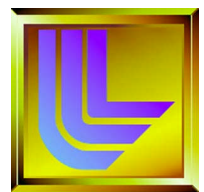




\section{AFM images from Tinsley AIA-1000-003 primary}

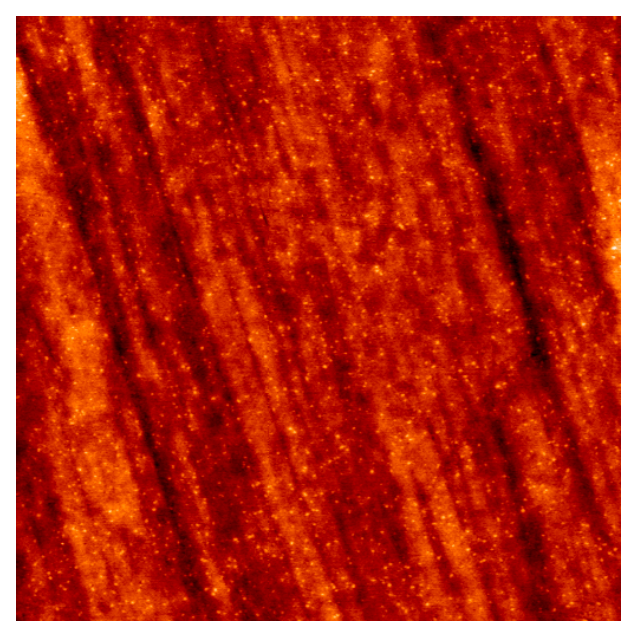

$2 \times 2 \mu \mathrm{m}^{2}$, loc. $\mathrm{H}$

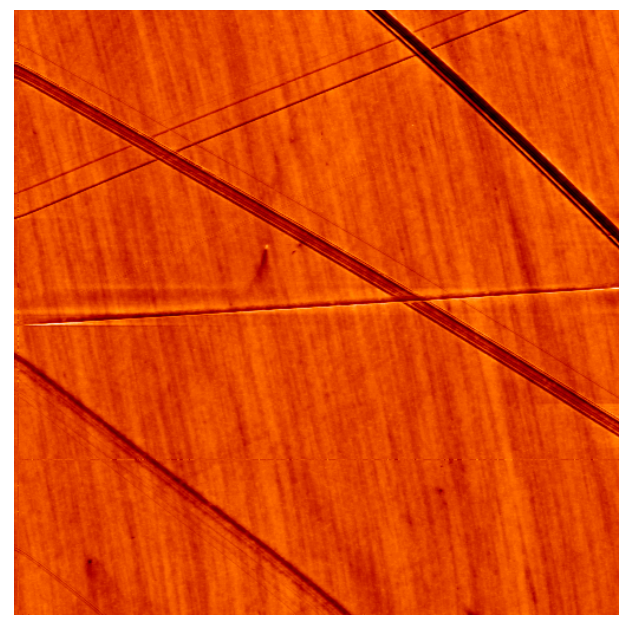

$10 \times 10 \mu \mathrm{m}^{2}$, loc. $\mathrm{H}$

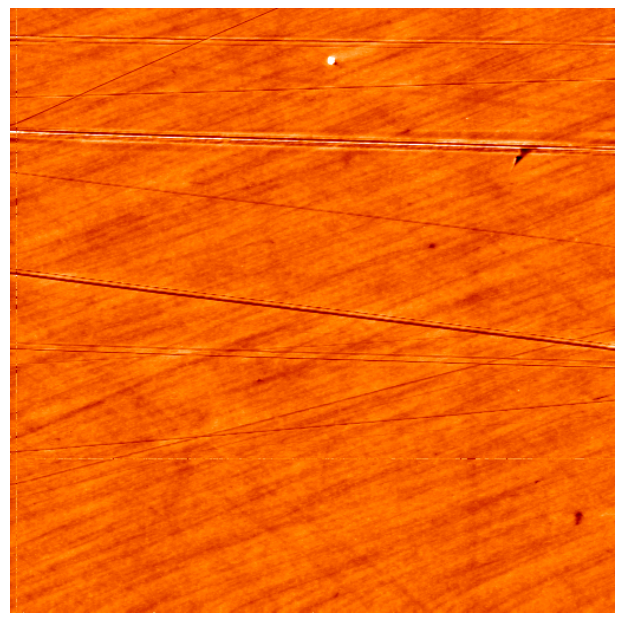

$10 \times 10 \mu \mathrm{m}^{2}$, loc. I

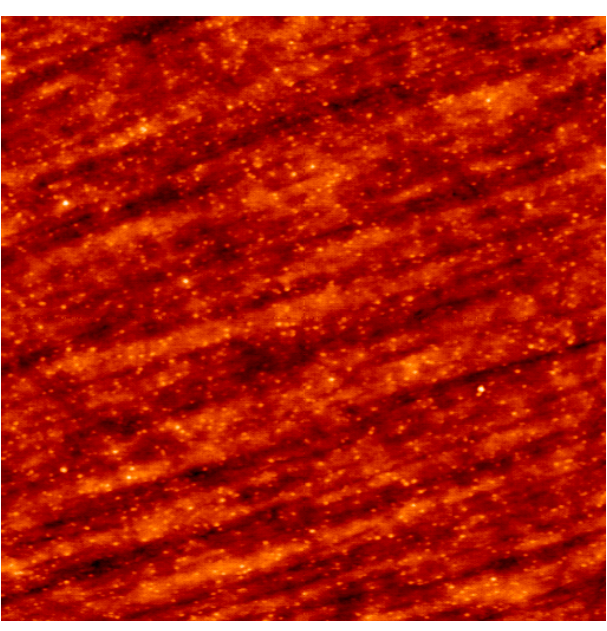

$2 \times 2 \mu \mathrm{m}^{2}$, loc. I

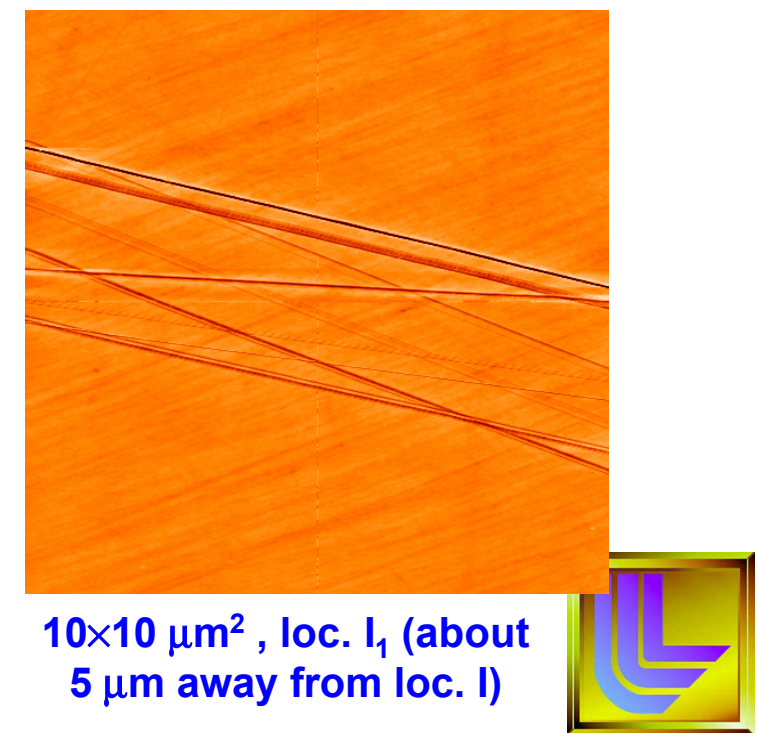

Regina Soufli et al, 10/20//05-01/13/06 


\section{Power Spectral Density (PSD) analysis of AFM data from}

Tinsley AIA-1000-003 primary substrate

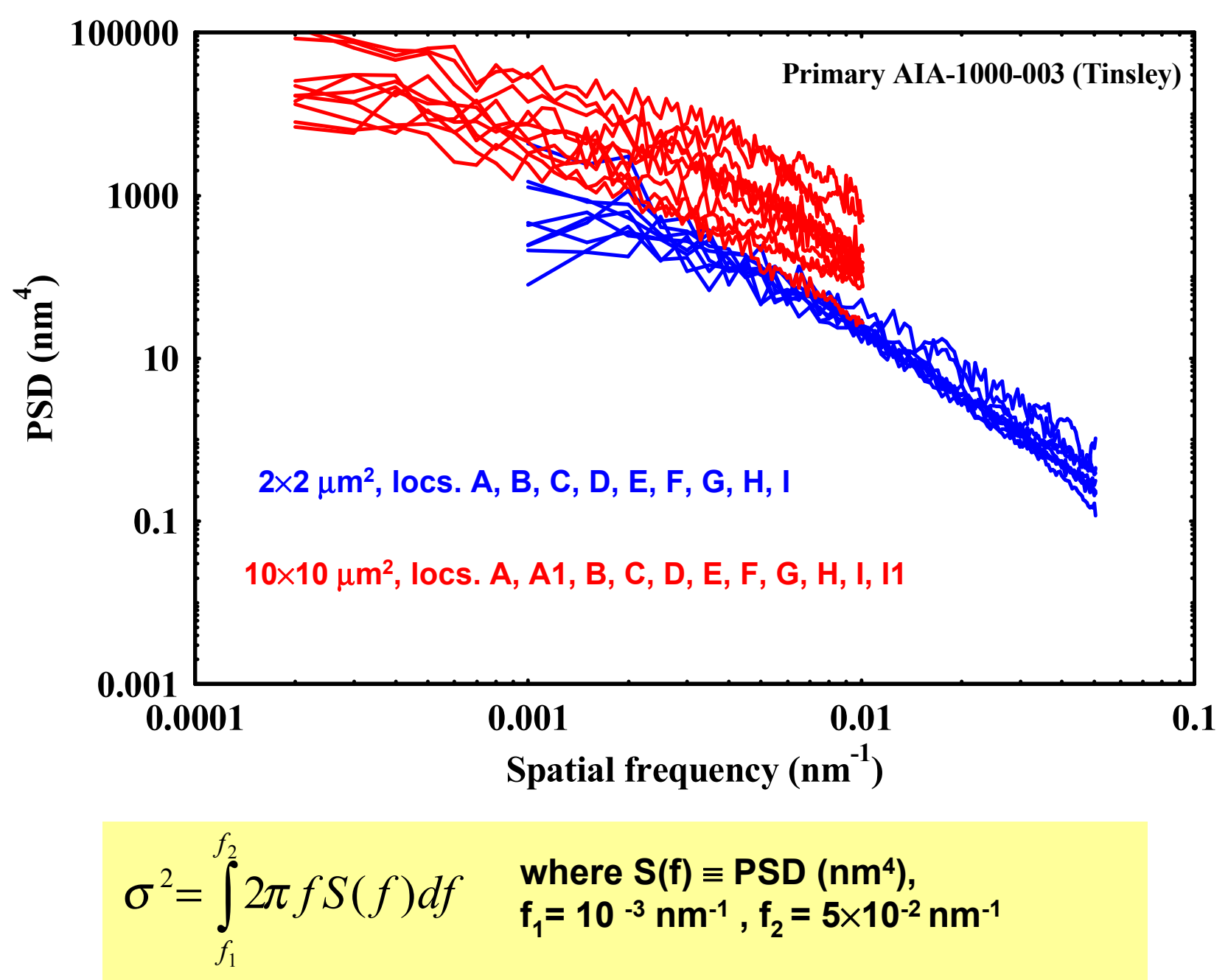

\begin{tabular}{|c|c|}
\hline Location & $\begin{array}{c}\sigma(\mathrm{nm} \\
\mathrm{rms})\end{array}$ \\
\hline A & 0.22 \\
\hline B & 0.22 \\
\hline C & 0.23 \\
\hline D & 0.22 \\
\hline E & 0.26 \\
\hline F & 0.25 \\
\hline G & 0.20 \\
\hline H & 0.22 \\
\hline I & 0.20 \\
\hline
\end{tabular}


2D PSD images vs. spatial frequency of $10 \times 10 \mu \mathrm{m}^{2}$ AFM scans from AIA-1000-003 Tinsley primary substrate

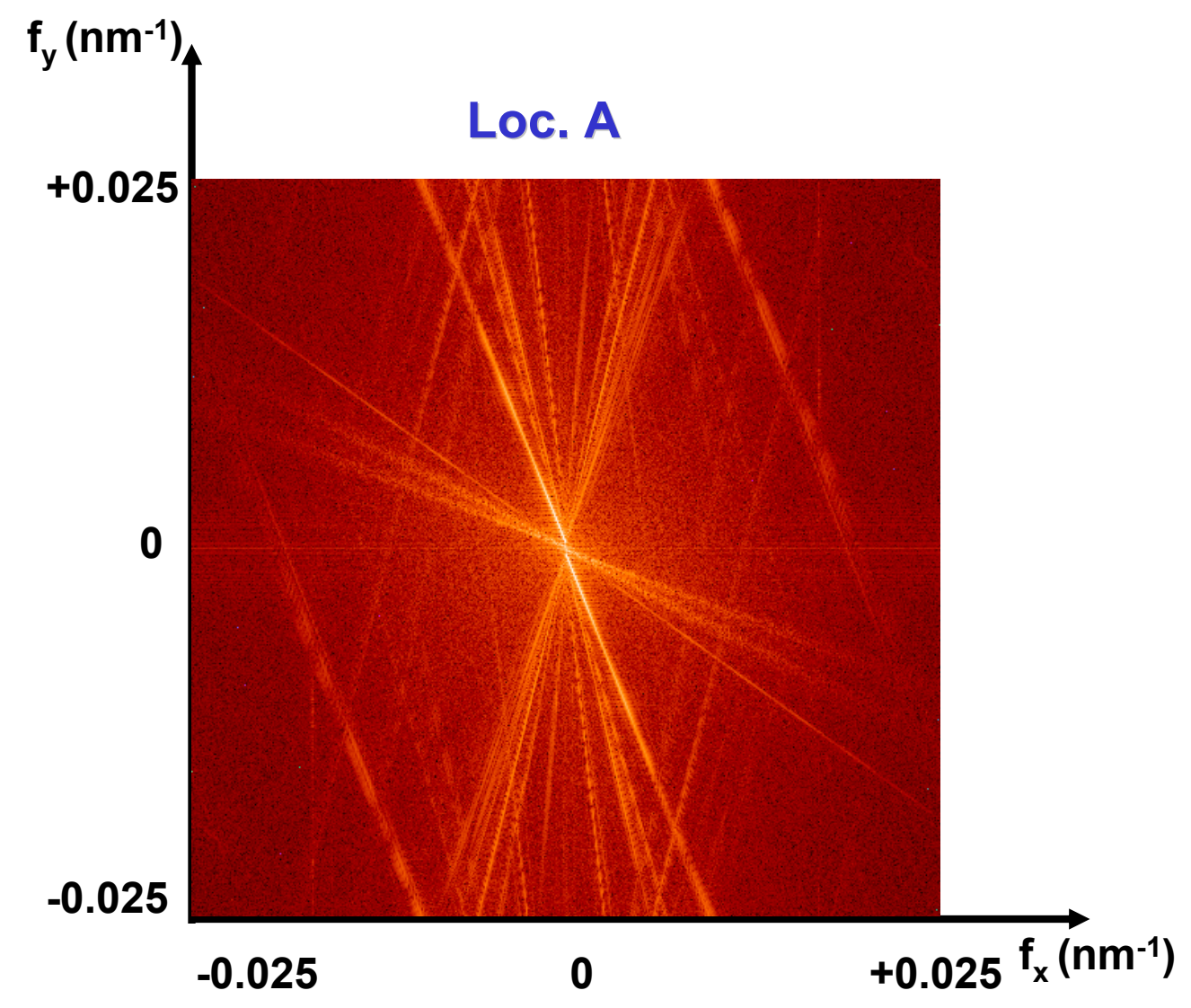

Loc. D
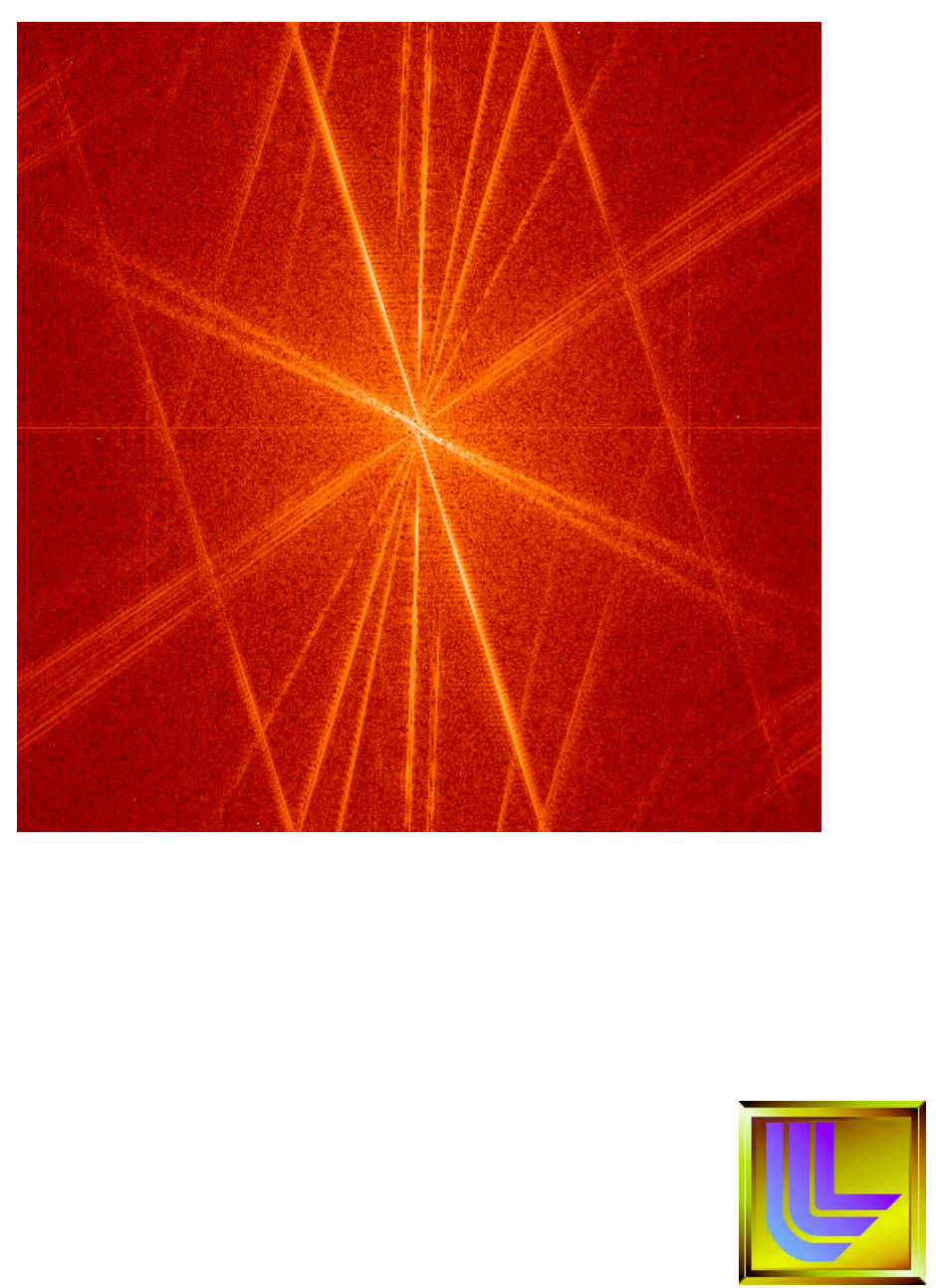


\section{Summary of AFM on Tinsley AIA-1000-003 primary (1)}

$>2 \times 2 \mu \mathrm{m}^{2}$ and $10 \times 10 \mu \mathrm{m}^{2}$ AFM measurements and analysis were performed on Tinsley AIA-1000-003 primary substrate at LLNL. The high-spatial frequency roughness $\sigma$ is estimated in the range $2-3 \AA \mathrm{rms}$, but the finish of this substrate is highly non-uniform, as is discussed below

$>$ In addition to the preferential direction in the polishing marks that we have also observed in earlier optics from the same vendor, there are pronounced "scratches" in random orientations and irregular spacing across the surface, apparent in all $10 \times 10 \mu \mathrm{m}^{2}$ AFM frames. The depth of each of these features is in the 50-150 A range, and their presence could cause some reduction of the reflectance of the multilayer-coated mirror

$>$ The irregular presence of these features is responsible for the poor overlap among the PSD curves extracted from the $10 \times 10 \mu \mathrm{m}^{2}$ AFM data

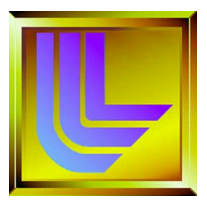




\section{Summary of AFM on Tinsley AIA-1000-003 primary (2)}

$>$ As with all AlA substrates, the orientation of the optic was maintained the same between AFM measurements on locations A, B, C, D, E. The optic was rotated between measurements on locations $F, G, H, I$.

$>$ All data were obtained with a Digital Instruments Dimension 5000 atomic force microscope

$>$ Special thanks to D.L. Windt for crucial updates to the TOPO software for AFM data analysis 